\title{
KINETICS OF OXYGEN FORMATION AND DISSOLUTION ON PLATINUM ELECTRODES IN THE ELECTROLYSIS OF MOLTEN POTASSIUM BISULPHATE*
}

\author{
A. J. Arvia, A. J. Calandra and H. A. Videla \\ Instituto Superior de Investigaciones, Facultad de Química y Farmacia, \\ Universidad Nacional de La Plata, La Plata, Argentina
}

\begin{abstract}
The kinetics of electrochemical formation and dissolution of oxygen in the electrolysis of molten potassium bisulphate in the temperature range of $c a 230-330^{\circ} \mathrm{C}$ has been studied. The potentiostatic and galvanostatic polarization curves at high overvoltages fit a Tafel equation. The anodic slope is $R T / F$, and the cathodic slope $R T / 2 F$.

At low anodic overvoltages oxide-film formation seems to occur on the platinum. In the cathodic overvoltage region dissolution of oxygen occurs with a well defined limiting cd related to the amount of oxygen dissolved in the melt.

Non-steady measurements for the anodic reaction yield kinetic parameters which coincide with those obtained from polarization curves. Experimental capacitances have reasonable low values.

Anodic results are discussed in terms of the discharge of sulphate or bisulphate ions on a totally oxidized platinum surface, the rate-determining step being a two-electron transfer.

The cathodic reactions comprise a diffusion process related to oxygen dissolution and the already known electrochemical formation of hydrogen.
\end{abstract}

Résumé- La cinétique des formation et dissolution électrochimique de l'oxygène a été étudiée au cours de l'électrolyse de sulfate acide de potassium fondu à des températures de 230 à $330^{\circ} \mathrm{C}$, par les méthodes électrochimiques habituelles.

Les courbes de polarisation potentiostatiques et galvanostatiques à hautes surtensions concordent avec l'equation de Tafel. Les pentes anodique et cathodique sont $R T / F$ et $R T / 2 F$ respectivement.

Une pellicule d'oxyde semble se former sur l'électrode de platine à des surtensions anodiques basses. Dans la même région de surtension cathodique l'oxygène se dissout et on observe une densité de courant limite bien établie liée à la quantité d'oxygène dissous dans le sel fondu.

Les mesures non-stationnaires pour la réaction anodique donnent des paramètres cinétiques en concordance avec ceux obtenus des courbes de polarisation. Les capacitances expérimentales donnent des valeurs basses.

On discute les résultats anodiques pour la décharge de l'ion sulfate ou bisulfate sur la surface de platine complètement oxydée, la réaction déterminante de la velocité étant une réaction de transfert de deux électrons.

Les réactions cathodiques comprennent un processus de diffusion lié à la dissolution de l'oxygène et à la formation électrochimique de l'hydrogène déjà etudiée.

Zusammenfassung-Die Kinetik der elektrochemischen Sauerstoff bildung und -auflösung während der Elektrolyse von geschmolzenem Kaliumbisulphat wurde mit den üblichen elektrochemischen Verfahren bei Temperaturen von ungefähr 230 bis $330^{\circ} \mathrm{C}$ untersucht.

Die potentio- und galvanostatischen Polarisationskurven bei hohen Überspannungen ergeben eine Tafelgleichung. Das Anodengefälle ist $R T / F$ und das Kathodengefälle $R T / 2 F$.

Bei niedrigen Anodenüberspannungen scheint sich auf der Platinelektrode ein Oxydfilm zu bilden. Im entsprechenden Kathodenüberspannungsgebiet wird der Sauerstoff aufgelöst und eine eindeutig eingestellte Stromdichte beobachtet, welche der aufgelösten Sauerstoffmenge entspricht.

Nicht stationäre Messungen der anodischen Reaktion vermitteln kinetische Parameter welche mit den aus Polarisationskurven erhaltenen übereinstimmen. Experimentelle Kapazitäten zeigen ziemlich niedrige Werte auf.

Es werden die Anodenergebnisse der Entladung von Sulphat oder Bisulphationen an einer völlig oxidierten Platinfläche, mit einer zwei-Elektronen Ubertragungsreaktion als geschwindigkeitsbestimmende Stufe, besprochen.

Die Kathodenreaktionen umfassen einen Diffusionsprozess welcher mit der Sauerstoffauflösung und der schon untersuchten elektrochemischen Wasserstoff bildung verbundenen ist.

* Manuscript received 17 April 1967. 


\section{INTRODUCTION}

DURING the electrolysis of molten potassium bisulphate on platinum electrodes, hydrogen is formed at the cathode and oxygen at the anode, in ratio of $2: 1$, as in the decomposition of sulphuric acid.1.2

The kinetics of the cathodic reaction occurring in that system was treated in more detail than the anodic reaction, as it was studied under different experimental conditions using various sorts of electrode materials, particularly bright platinum and platinized-platinum electrodes. ${ }^{3-5}$ More recently the effect of the electrode nature on the reaction was also studied, ${ }^{6}$ yielding a further understanding of the activated electrode process. In spite of these contributions, however, additional information about the actual ionic species participating in the initial discharge process is still required to define the reaction mechanism unambiguously. Further knowledge of the structure of the melt, gained quite recently, ${ }^{7}$ helps for this purpose.

The anodic reaction occurring in the electrolysis of the melt has not yet been studied in this way. It might be expected that the anodic reaction would be complicated, like oxygen evolution on platinum in aqueous solution, ${ }^{8}$ because of the several possible oxidation states of the platinum electrode, which may affect the electrode reaction appreciably. ${ }^{9-10}$

The electrochemical formation of oxygen in the electrolysis of molten potassium bisulphate is of particular interest because of peculiarities earlier observed in the current/voltage curves obtained with melts containing oxy-anions. ${ }^{11}$ There, at low dc, the electrochemical process is under convective-diffusion control, while at higher dc it becomes an activated electrode process. The probable participation of the oxide ion has been postulated. ${ }^{12}$

The present study also comprises information about the cathodic dissolution of oxygen in the melt and adds complementary information on the hydrogen-evolution reaction earlier reported. A better knowledge of the melt structure allows us to explain the reaction mechanism not merely in formal terms but in better agreement with the intrinsic phenomena. New information to be communicated later ${ }^{13}$ has helped to interpret the present work.

\section{EXPERIMENTAL TECHNIQUE}

The electrolysis cell was of Pyrex glass, with a design similar to that described in earlier publications. ${ }^{\mathbf{1 4 . 1 5}}$ Bright platinum wires whose geometrical areas were between 1.0 and $3.0 \mathrm{~cm}^{2}$ were used as anodes. The electrodes were first polished with a mixture of alumina and alcohol, then cleaned with distilled water and finally dried prior to the immersion into the melt. Then, the working electrode was either made the cathode of the cell for a certain time to achieve a reduction of the electrode surface in situ, during hydrogen evolution, or its anode, so that it was oxidized to a certain extent.

The cathode also consisted of a bright platinum wire placed into a separate compartment, avoiding as far as possible any appreciable diffusion of hydrogen gas into the anodic section of the cell.

The reference electrode was a platinized platinum electrode dipped into the melt. This was continuously saturated with purified hydrogen gas at atmospheric pressure. It was connected to the rest of the system by the usual Luggin-Haber capillary tip arrangement. ${ }^{4}$ 
Potassium bisulphate (AR, Mallinckrodt), purified and vacuum-dried at room temperature for several weeks was used. The melt was further kept at the temperature of the experiments for $48 \mathrm{~h}$ at least, before starting measurements.

Temperature was varied from 230 to $330^{\circ} \mathrm{C}$. Before an experiment, the cell was saturated with highly purified nitrogen. Later the reference electrode was saturated with purified hydrogen while the working electrode section of the cell was saturated either with purified oxygen or with nitrogen. In other cases, no gas was passed through. In some cases it was necessary to produce oxygen in situ by electrolysis prior to the experiments.

Steady and non-steady electrochemical measurements were made. The former comprised current/voltage curves recorded either galvanostatically or potentiostatically and by raising or lowering the $\mathrm{cd}$. The latter involved the determination of build-up and decay of electrode potential. Details of the instrumentation have been described. ${ }^{14.15}$

\section{RESULTS}

\section{Current/voltage curves}

A typical set of voltage/log cd curves, obtained with molten potassium bisulphate saturated with oxygen, is shown in Fig. 1, comprising both the anodic and the cathodic regions. Figure 2 presents another set of curves obtained with the melt saturated with nitrogen. Anodic polarization curves in a semi-logarithmic plot are also represented in Fig. 3.

The anodic curves show three well-defined regions. At cds lower than $10 \mu \mathrm{A} / \mathrm{cm}^{2}$, in spite of the larger errors affecting the results, the plot involves an increasing slope in the voltage/log $i$ plot, pointing to a limiting cd. This portion extends up to an overvoltage of about $200 \mathrm{mV}$. Beyond this value, for a current density range covering from 10 to about $10^{5} \mu \mathrm{A} / \mathrm{cm}^{2}$, the voltage $/ \log i$ plot fits a Tafel relationship

$$
\eta=-\frac{2 \cdot 3 R T}{\alpha_{\mathrm{a}} F} \log i_{0}+\frac{2 \cdot 3 R T}{\alpha_{\mathrm{a}} F} \log i
$$

The overvoltage, $\eta$, is defined as

$$
\eta=E-E_{\infty},
$$

where $E$ is the electrode potential giving an apparent cd $i ; E_{\infty}$ is the rest potential of the working electrode measured against the reference electrode. $i_{0}$ is the apparent exchange current density, $\alpha_{\mathrm{a}}$ the transfer coefficient assisting the anodic reaction in the forward direction and the rest of the symbols have their usual meanings. The Tafel slope, $2 \cdot 3 R T / \alpha_{\mathrm{B}} F$, is indicated as $b_{\mathrm{T}}$.

At the highest current densities another departure from the Tafel line is observed. This fact, which is related to some instability in the current intensity, may be in part due to bubble formation and in part to a change of the apparent electrode area.

As shown in Figs. 1-3, a slight difference is observed between potentiostatic and galvanostatic experiments in the Tafel region. The same is true for experiments done with raising and lowering of the cd. The situation is quite different at lower cds. Here, when the current density is lowered, overvoltages are higher than those when the current is raised. This sort of hysteresis suggests a definite modification of the electrode surface when large positive potentials are applied to the working electrode; 


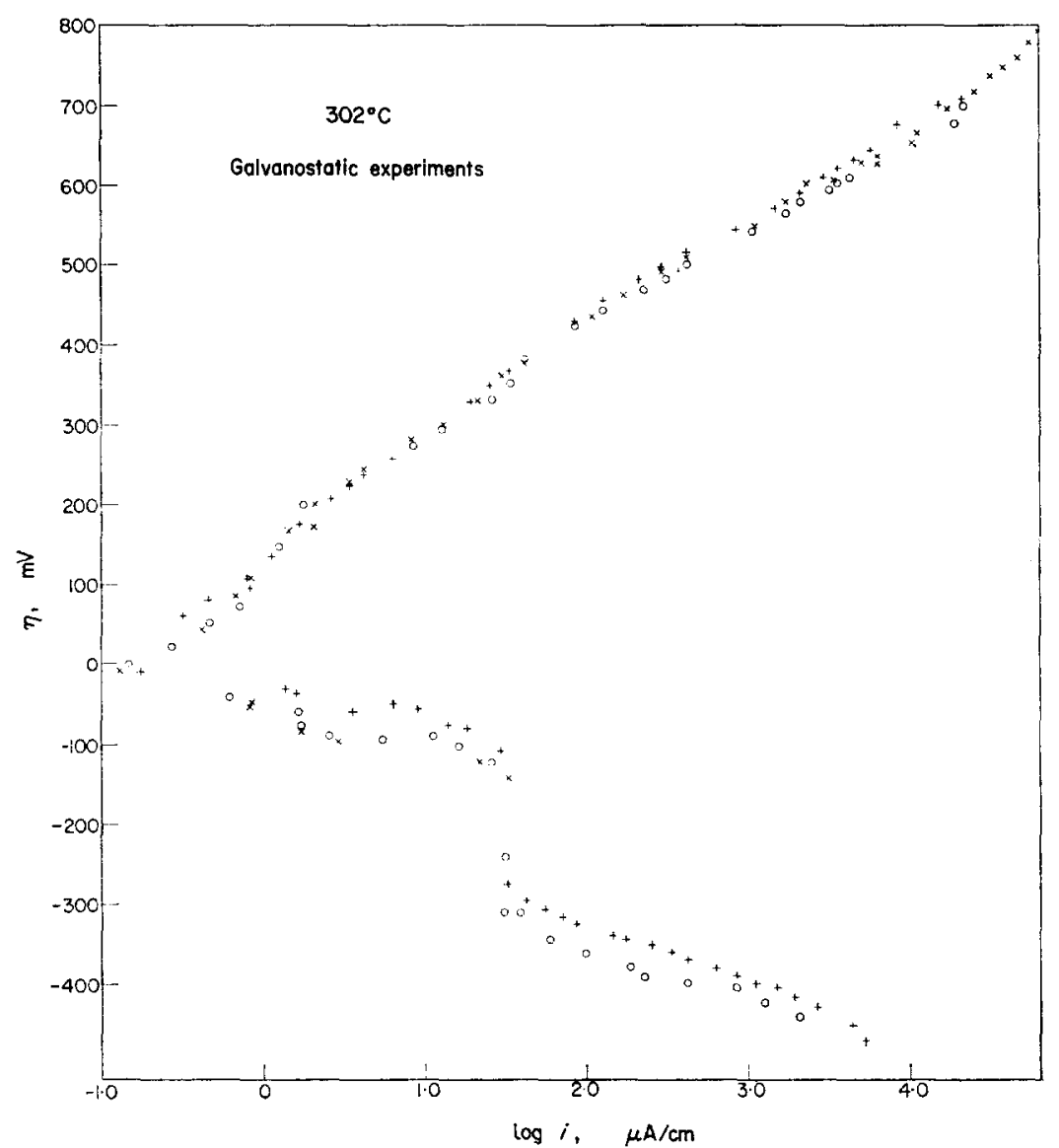

FIG. 1. Anodic and cathodic current/voltage curves. Melt saturated with oxygen at 1 atm pressure.

it is still more evident when the anodic polarization curve is started within the negative potential region, as shown in the figures.

The anodic region of the voltage/log $i$ plot which yields a satisfactory straight line exhibits a slope very close to $2 \cdot 3 R T / F$. Values of $b_{\mathrm{T}}$ and $i_{0}$ obtained by extrapolating this line to the rest potential are assembled in Table 1. It should be noted that this part of the polarization curve is modified neither when oxygen or nitrogen saturates the melt nor when the rate of gas bubbling is changed.

Cathodic current/voltage curves were obtained with the melt continuously saturated with oxygen or with nitrogen. Again, the data related to the initial part of the curve are less reproducible than those obtained at more negative potentials. The cathodic curve also comprises three well defined regions. At lower cds, in spite of some scatter, it is possible to establish a linear relationship between $\eta$ and $\log i$, but it is difficult to give any certain slope. Beyond $20 \mu \mathrm{A} / \mathrm{cm}^{2}$, the cathodic curve exhibits a sudden increase of overvoltage. This region is probably preceded by another where some depolarizing effect is also present. The potential jump is related to a limiting cd which depends on the oxygen concentration in the melt. For a $1 \mathrm{~atm}$ oxygen, the limiting $\mathrm{cd}$ at $302^{\circ} \mathrm{C}$ is $31 \mu \mathrm{A} / \mathrm{cm}^{2}$, as shown in Fig. 1. 


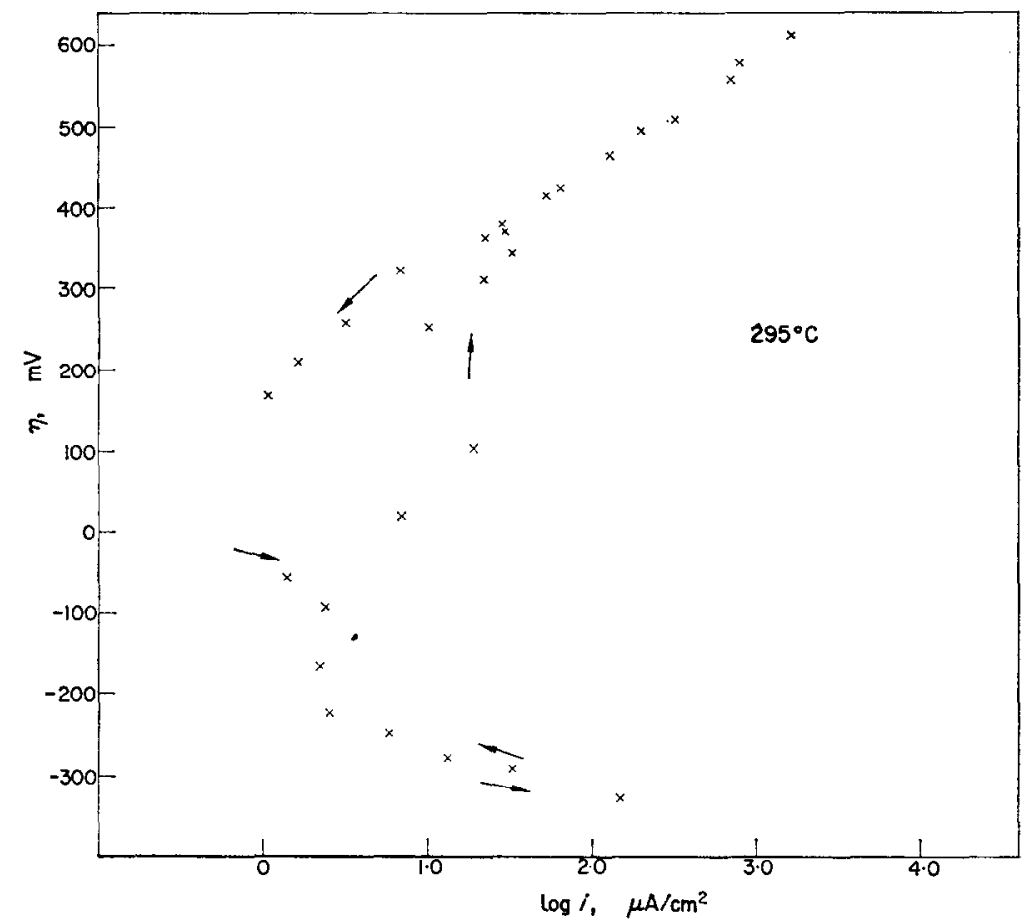

FIG. 2. Anodic and cathodic current/voltage curves. Melt saturated with nitrogen at 1 atm pressure. Arrows indicate direction of current change.

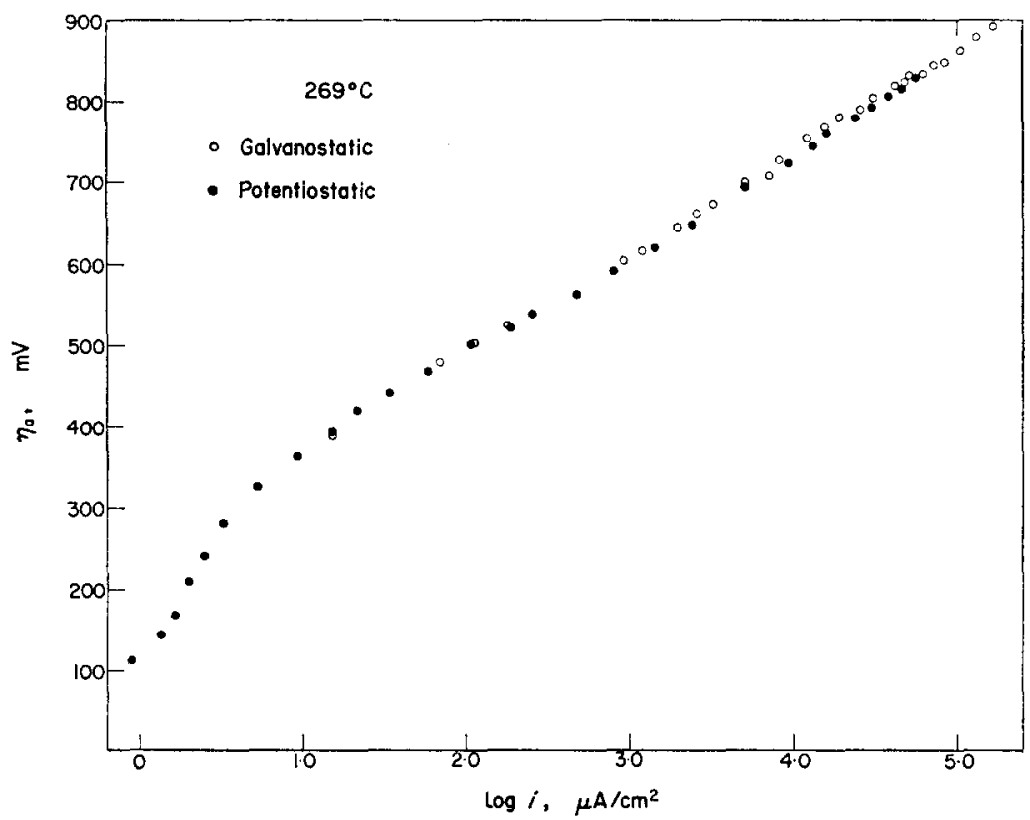

Fig. 3. Anodic current/voltage curve. 
Table 1. Data from anodic current/voltage CuRves

\begin{tabular}{|c|c|c|c|c|}
\hline$\underset{{ }^{\circ} \mathrm{C}}{\text { Temp }}$ & $b_{\mathrm{T}} \times{ }_{\mathrm{V}} 10^{\mathrm{a}}$ & $\underset{\mathrm{V}}{(2 \cdot 3 R T / F)} \times 10^{3}$ & $\begin{array}{c}\log i_{0} \times 10^{\circ} \\
\text { average }\end{array}$ & Exp. details \\
\hline $233 \pm 0.5$ & $115 \pm 10$ & $100 \cdot 4$ & 0.55 & $\mathbf{P}$ \\
\hline 263 & $115 \pm 10$ & $106 \cdot 4$ & 0.80 & $\mathrm{P}, \mathrm{N}_{2}$ \\
\hline 263 & $120 \pm 10$ & $106 \cdot 4$ & 0.60 & $\mathbf{P}$ \\
\hline 269 & $115 \pm 5$ & 107.6 & 0.70 & G, P \\
\hline 270 & $111 \pm 5$ & 107.8 & $0 \cdot 70$ & $\mathrm{G}, \mathrm{P}$ \\
\hline 302 & $120 \pm 5$ & $114 \cdot 1$ & 1.72 & $\mathrm{G}, \mathrm{O}_{2}$ \\
\hline 320 & $110 \pm 10$ & 116.7 & 2.69 & $\mathbf{P}$ \\
\hline
\end{tabular}

$G$, galvanostatic experiments; P, potentiostatic experiments.

With the melt saturated with nitrogen, the limiting cd at $295^{\circ} \mathrm{C}$ was of $c a 1 \mu \mathrm{A} / \mathrm{cm}^{2}$, a small value which should be considered zero within experimental error. It is reasonable to conclude, therefore, that this portion of the cathodic polarization curves is related to the reduction of molecular oxygen dissolved in the melt.

On increasing the cathodic potential a third region of the voltage/log $i$ plot is observed which fits another Tafel line, having a slope of $2 \cdot 3 R T / 2 F$. This cathodic line is unaffected by changing the current intensity in either direction and corresponds to the evolution of hydrogen gas.

\section{Temperature effect on current/voltage curves}

The temperature effect was preferentially studied in the anodic experiments and in the region of the Tafel line. No change of the anodic Tafel slope was observed in the temperature range studied, suggesting at first sight that no fundamental changes in the electrochemical reaction due to temperature modification takes place. At constant overvoltage, the cd increases with temperature according to an Arrhenius equation. The experimental activation energies at different overvoltages, deduced from data assembled in Table 2, are indicated in Table 3.

The dependence of the apparent exchange cd on temperature, as it involves a relatively large error because of the fluctuations often noticed in the rest potential, was not considered in evaluating the experimental activation energies.

TABle 2. Dependence OF ANODIC CD ON TEMPERATURE AT DIFFERENT OVERVOLTAGES

\begin{tabular}{cccc}
\hline $\begin{array}{c}\text { Temp } \\
{ }^{\circ} \mathrm{C}\end{array}$ & $\begin{array}{c}(i)_{\eta=400 \mathrm{mv}} \\
\mu \mathrm{A} / \mathrm{cm}^{2}\end{array}$ & $\begin{array}{c}(i)_{\eta=500 \mathrm{mv}} \\
\mu \mathrm{A} / \mathrm{cm}^{2}\end{array}$ & $\begin{array}{c}(i)_{\eta=800 \mathrm{mv}} \\
\mu \mathrm{A} / \mathrm{cm}^{2}\end{array}$ \\
\hline 233 & $11 \cdot 9$ & $63 \cdot 8$ & 403 \\
269 & $16 \cdot 4$ & 159 & 1039 \\
302 & $66 \cdot 7$ & 421 & 2660 \\
320 & 100 & 794 & 8050 \\
\hline
\end{tabular}

TABLE 3. EXPERIMENTAL ACTIVATION ENERGIES

\begin{tabular}{cc}
$\eta \times 10^{3}$ & $\Delta E_{\mathrm{a}}$ \\
$\mathrm{V}$ & $\mathrm{Kcal} /$ mole \\
\hline 400 & $14 \pm 3$ \\
500 & $18 \pm 3$ \\
600 & $17 \pm 3$ \\
\hline
\end{tabular}




\section{Decay of anodic overvoltage}

Typical decay curves of the anodic overvoltage are shown in Figs. 4 and 5, obtained in the region of the anodic Tafel line under different experimental conditions. They show a particularly simple relationship between the electrode overvoltage, $\eta$, and time, $t$, of the form already known:

$$
\eta=A-b_{\mathrm{d}} \log \left(t+t^{\prime}\right),
$$

where $t^{\prime}$ is a constant involving the electrode capacitance with a value smaller than one $\mathrm{ms}, b_{\mathrm{d}}$ is the slope of the decay curve in the semi-logarithmic plot and $A$ is a constant depending on the initial potential, the current intensity at the interruption, the electrode capacitance and the constant $b_{\mathrm{d}}{ }^{16}$

Since the range of $t$ where the decay curve was measured is much larger than $t^{\prime}$, the voltage/ $\log t$ plot shows a linear relationship over six logarithmic decades. The linear region is well characterized by a slope close to $2 \cdot 3 R T / F$, which appears independent of the current intensity previously passed through the cell. The slope remains the same at the different temperatures investigated and no dependence on the oxygen or nitrogen gas saturation was detected. It was also observed that decay curves in this region of the anodic potential yield a slope which agrees satisfactorily with the Tafel slope of the current/voltage curves in the same region. At values of $t$ close to $t^{\prime}$ or lower, the curve approaches asymptotically the initial overvoltage in the semilogarithmic plot.

At the other extreme, at low overvoltages, when the electrode potential approaches the rest potential, another deviation from the straight line is observed. That deviation,

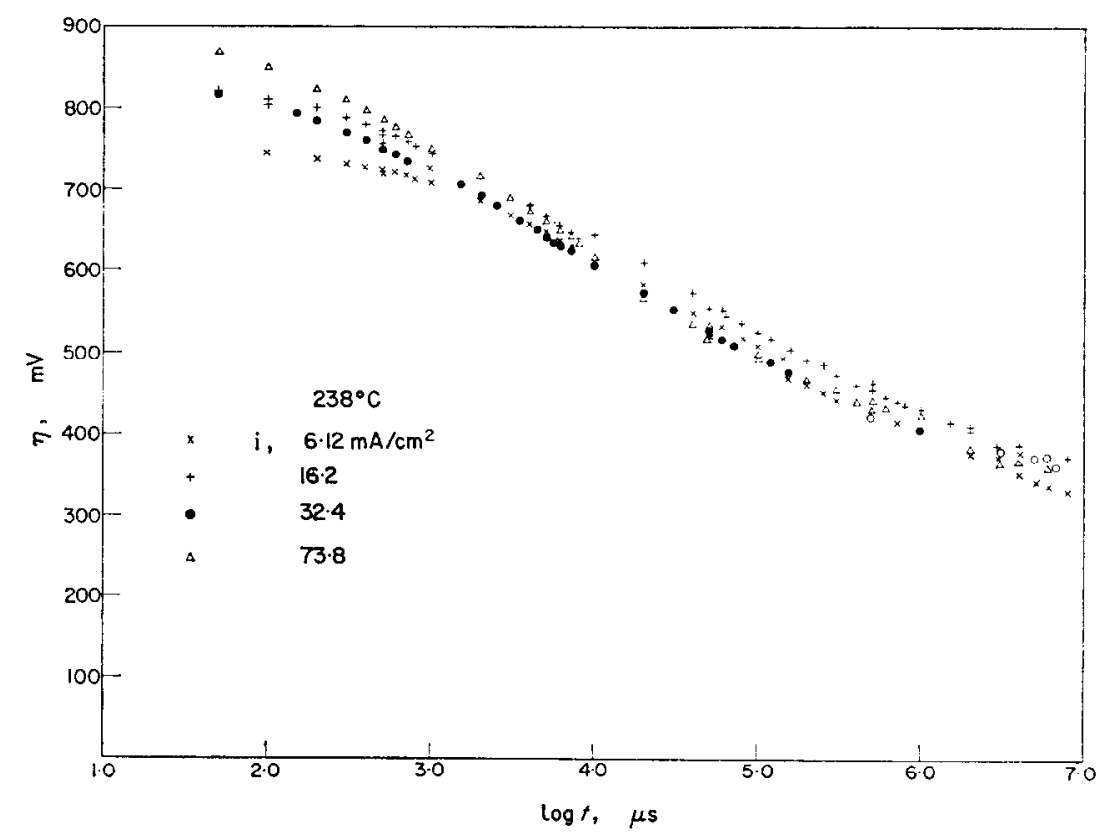

FIG. 4. Semi-logarithmic plot of decay curves. 


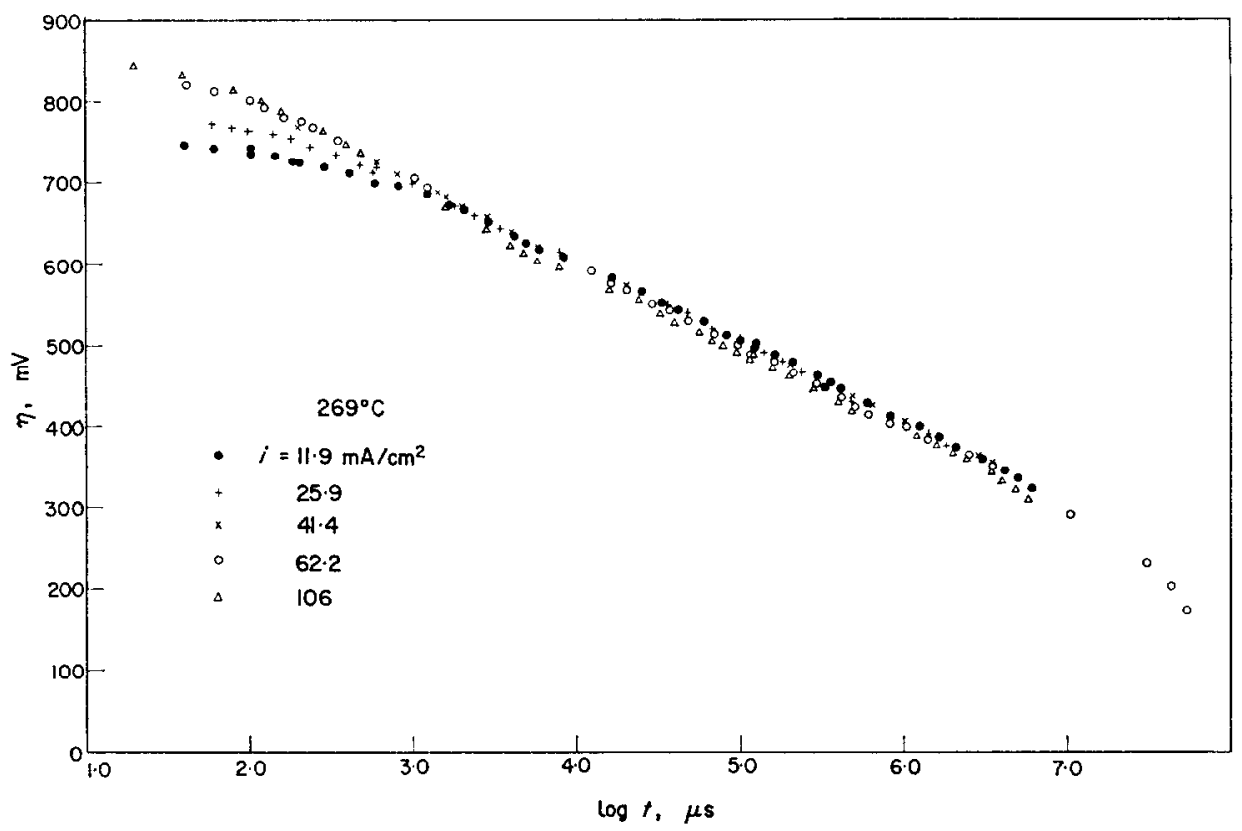

Fig. 5. Semi-logarithmic plot of decay curves.

however, is not very reproducible, as was the case with data of current/voltage curves in the same potential region.

The electrode capacitance, $C$, was evaluated from the decay curves either from $t^{\prime}$, according to

$$
C=2 \cdot 3 \frac{i t^{\prime}}{b_{\mathrm{d}}},
$$

or from the initial slope of the decay curves,

$$
C=|i|\left(\frac{\mathrm{d} t}{\mathrm{~d} \eta}\right)_{t=0} .
$$

Both equations give similar results, the electrode capacitance being referred to the electrode potential at current interruption. Parameters obtained from anodic decay curves are assembled in Table 4. No definite dependence of the electrode capacitance on electrode potential was noticed.

\section{Build-up of anodic overvoltage}

Galvanostatic build-up curves are shown in Figs. 6 and 7. Decay curves are also shown in Fig. 6. Build-up curves of anodic overvoltage show initially a linear increase of potential with time, reaching a limit value after about $10 \mathrm{~ms}$. The initial slope of build-up curves was used to evaluate the electrode capacitance at the initial potential. Values of $C$ estimated from build-up curves are indicated in Table 5. They are similar to those already reported in Table 4. 
Table 4. Data from anodic overvoltage decay

\begin{tabular}{|c|c|c|c|}
\hline $\begin{array}{c}i \times 10^{3} \\
\mathrm{~A} / \mathrm{cm}^{2}\end{array}$ & $b_{\mathrm{d}} \times{ }_{\mathrm{V}} 10^{\mathrm{s}}$ & $t^{\prime} \times 10^{8}$ & $\begin{array}{c}C \times 10^{6} \\
\mathrm{~F} / \mathrm{cm}^{2}\end{array}$ \\
\hline \multicolumn{4}{|c|}{ Temp $238^{\circ} \mathrm{C}$} \\
\hline $\begin{array}{l}6 \cdot 12 \\
16 \cdot 2 \\
32 \cdot 4 \\
73 \cdot 8\end{array}$ & $\begin{array}{l}116 \pm 5 \\
116 \\
116 \\
116\end{array}$ & $\begin{array}{r}560 \\
214 \\
96 \\
45\end{array}$ & $\begin{array}{l}68 \\
69 \\
62 \\
66\end{array}$ \\
\hline \multicolumn{4}{|c|}{ Temp $269^{\circ} \mathrm{C}$} \\
\hline $\begin{array}{c}11 \cdot 9 \\
25 \cdot 9 \\
41 \cdot 4 \\
62 \cdot 2 \\
106\end{array}$ & $\begin{array}{l}120 \pm 5 \\
120 \\
120 \\
120 \\
120\end{array}$ & $\begin{array}{c}250 \\
126 \\
90 \\
63 \\
31 \cdot 5\end{array}$ & $\begin{array}{l}57 \\
63 \\
72 \\
75 \\
64\end{array}$ \\
\hline
\end{tabular}
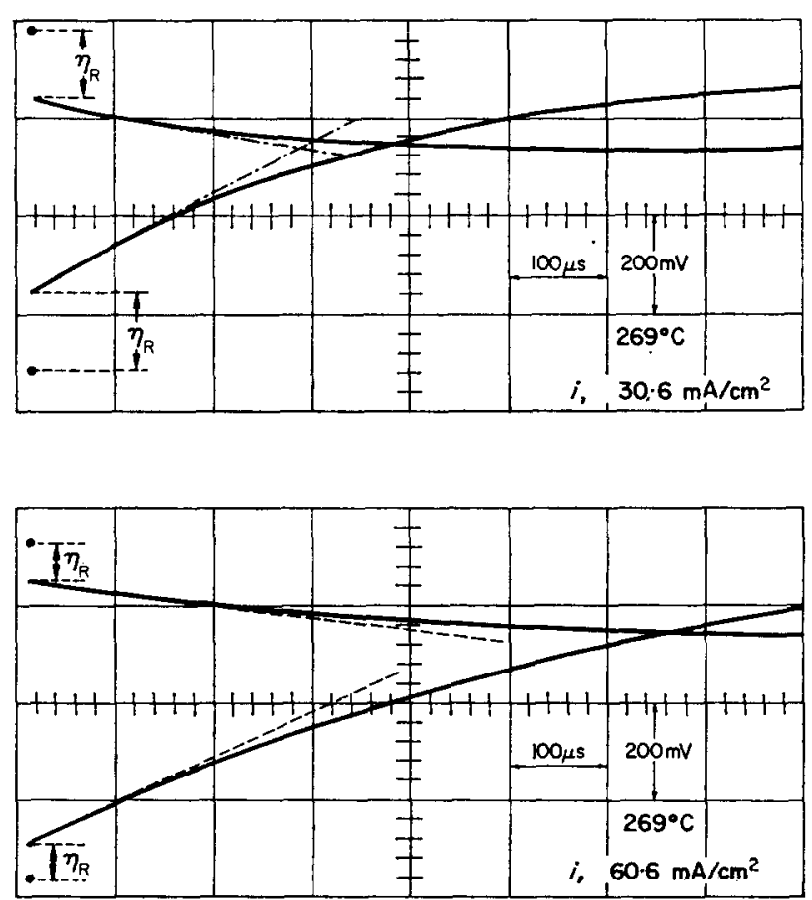

FIG. 6. Galvanostatic build-up and decay of anodic overvoltages.

\section{Build-up of cathodic overvoltage}

Galvanostatic build-up curves were recorded with the melt saturated with oxygen. They are characterized by the existance of a transition time, $\tau$, clearly shown in Fig. 7. The transition time decreases as cd increases. Data from cathodic build-up curves are shown in Table 6 . Obviously the product $i \tau^{\mathbf{1 / 2}}$ is not fully meaningful since the diffusion process occurring here may be considerably complex due to cell design. 

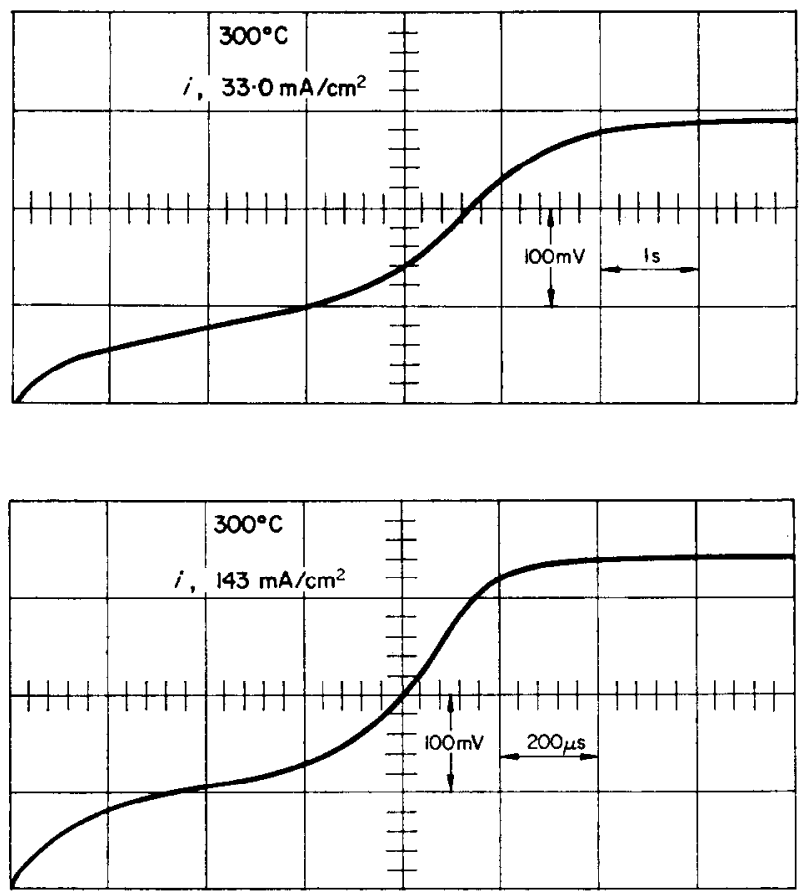

FIG. 7. Galvanostatic build-up of cathodic overvoltages.

The cathodic build-up curves can be directly compared with the corresponding current/voltage curves. The half-wave cathodic overpotential for the melt saturated with oxygen at atmospheric pressure is $90 \pm 10 \mathrm{mV}$. This figure agrees with the potential read on build-up curves for $\tau_{1 / 4}$.

\section{The residual potential}

The rest potentials, read after current interruption, between the anode and the reference electrode are shown in Table 7 . They are apparently very sensitive to any change or treatment of the electrode surface and are also temperature-dependent. Those potentials were taken as a reference to define the electrode overvoltages. The

Table 5. Capacitances from build-up curves at THE INITIAL POTENTIAL

\begin{tabular}{ccc}
\hline $\begin{array}{c}\text { Temp } \\
{ }^{\circ} \mathrm{C}\end{array}$ & $\begin{array}{c}i \times 10^{3} \\
\mathrm{~A} / \mathrm{cm}^{2}\end{array}$ & $\begin{array}{c}\mathrm{C} \times 10^{6} \\
\mathrm{~F} / \mathrm{cm}^{2}\end{array}$ \\
\hline 238 & 16.2 & 59 \\
& 16.2 & 63 \\
& 32.4 & 73 \\
& 75.6 & 68 \\
& 11.9 & 66 \\
& 25.9 & 61 \\
& 30.6 & 61 \\
319 & 60.6 & 61 \\
& 41.2 & 57 \\
& 48.7 & 67 \\
\hline
\end{tabular}


Table 6. Data From cathodic galvanostatic Build-up CURVES IN THE PRESENCE OF OXYGEN SATURATING THE MELT

\begin{tabular}{ccc}
$P_{\mathrm{O}_{3}}=1 \mathrm{~atm}$ & Temp $300^{\circ} \mathrm{C}$ & $E_{\tau=1 / 4} \times 10^{3}$ \\
$i \times 10^{\mathrm{s}}$ & $\mathrm{s}$ & $\mathrm{V}$ \\
$\mathrm{A} / \mathrm{cm}^{2}$ & 4.80 & $80 \pm 10$ \\
\hline 18.5 & 3.35 & 80 \\
33.0 & 1.40 & 80 \\
71.4 & 0.60 & 100 \\
143 & 0.35 & 100 \\
248 & 0.26 & 110 \\
336 & 0.25 & 110 \\
378 & & \\
\hline
\end{tabular}

Table 7. Potentials of Residual cells

\begin{tabular}{cll}
\hline $\begin{array}{c}\text { Temp } \\
{ }^{\circ} \mathrm{C}\end{array}$ & $\begin{array}{c}E_{\infty} \times 10^{3} \\
\mathrm{~V}\end{array}$ & Experimental conditions \\
\hline 233 & $360 \pm 5$ & no oxygen bubbling \\
246 & 520 & no oxygen bubbling \\
270 & 480 & no oxygen bubbling \\
295 & 450 & no oxygen bubbling \\
295 & 420 & oxygen bubbling \\
302 & 400 & oxygen bubbling \\
315 & 420 & no oxygen bubbling \\
321 & 486 & no oxygen bubbling \\
\hline
\end{tabular}

rest potentials obtained from the cathodic as well as the anodic side at constant temperature were coincident when several hours had elapsed after current interruption.

\section{DISCUSSION}

At low anodic and cathodic cds the results obtained when the current is raised and lowered are not completely coincident. At higher cds both cathodic and anodic regions involve a range where Tafel lines with well-defined and reasonable slopes cxist.

The anodic Tafel slope, $R T / F$, agrees with the results earlier reported by other authors, who in the study of oxygen overvoltage in molten salts, indicated a Tafel slope of $200 \mathrm{mV}$ at $700^{\circ} \mathrm{C}$, with the lithium sulphate-sodium sulphate $(2: 3)$ melt, ${ }^{11}$ this slope being associated with an activated process. A reliable proof of the existence of the activated process in the oxygen-evolution reaction at high temperatures is found in the effect of the nature of the electrode surface on the kinetics of the reaction, as will be reported.

The state of the electrode surface must be taken into account. A good deal of information is now available on the platinum-oxygen system. ${ }^{17-19}$ Under ordinary conditions a monolayer film of chemisorbed oxygen is formed on the platinum surface, whose nature is still not unambiguously determined; it is either an oxide layer or a layer of oxygen atoms. ${ }^{20.21}$ The role played by surface oxides in a number of electrochemical reactions has been reconsidered recently, ${ }^{22}$ particularly in the kinetics of the oxygen dissolution $^{23}$ and oxygen evolution ${ }^{24}$ in the electrolysis of aqueous solutions on platinum electrodes. 


\section{Anodic reactions}

The current/voltage curves at low overvoltages were sensitive to electrode treatment, a feature which may be related to film formation. When the platinum electrode had been anodized or the polarization curve had been recorded from higher to lower positive potentials, the first region observed at low overvoltages became smaller. This behaviour suggests the existence of a film on the platinum electrode in the melt saturated with oxygen; like that known for the same electrode in aqueous solutions at ordinary temperatures, it is probably not much thicker than a monolayer. ${ }^{25}$ In the present case, at low anodic overvoltages the predominant species is probably of the type $\mathrm{PtO}$, while at potentials higher than $1.5 \mathrm{~V}$ (at least for aqueous systems), a conversion to $\mathrm{PtO}_{2}$ may occur. ${ }^{16.26}$

In the low overvoltage region, the apparent tendency to a limiting current exists and no passivation region appears. This means, as earlier observed in aqueous solutions, that the oxide film formed in this potential region behaves as a good electrical conductor, the conduction also being possibly due to the quantum-mechanical tunnel effect. ${ }^{25}$

We first consider how the initial oxide film is formed. The reaction, assuming a bare platinum surface, can proceed either through the discharge of a bisulphate or a sulphate ion. The direct discharge of the former would involve a rather elaborate mechanism to explain the observed Tafel slope at higher overvoltages, while the initial discharge of the latter may be easily accounted for if the acid-base equilibrium (I-1), shown below, is taken into account. Consequently, the following reaction paths can be postulated:

Scheme I:

$$
\begin{aligned}
2 \mathrm{HSO}_{4}^{-} & \rightleftharpoons \mathrm{SO}_{4}^{2-}+\mathrm{H}_{2} \mathrm{SO}_{4}, \\
\mathrm{SO}_{4}^{2-}+\mathrm{Pt} & \rightleftharpoons \mathrm{Pt}(\mathrm{O})+\mathrm{SO}_{3}+2 \mathrm{e}, \\
\mathrm{SO}_{3}+\mathrm{SO}_{4}^{2-} & \rightleftharpoons \mathrm{S}_{2} \mathrm{O}_{7}^{2-} .
\end{aligned}
$$

Scheme II:

$$
\begin{aligned}
& \mathrm{HSO}_{4}^{-}+\mathrm{Pt} \rightleftharpoons \mathrm{Pt}(\mathrm{O})+\mathrm{SO}_{3}+\mathrm{H}^{+}+2 \mathrm{e}, \\
& \mathrm{SO}_{3}+\mathrm{SO}_{4}^{2-} \rightleftharpoons \mathrm{S}_{2} \mathrm{O}_{7}^{2-}, \\
& \mathrm{H}^{+}+\mathrm{HSO}_{4}^{-} \rightleftharpoons \mathrm{H}_{2} \mathrm{SO}_{4} .
\end{aligned}
$$

Assuming that the rate determining step is the electron-transfer reaction (I-2) or (II-1), the reaction (I-1) becomes a fast reaction preceding the electrode surface oxidation, in scheme I. The formation of the oxide layer might also be considered to proceed via the oxide ion, originated from any of the oxy-anions present in the system.

All the rate-determining steps mentioned above imply the following features, which are reflected in the current/voltage curve at low positive overvoltages: (i) the rate of reaction depends on the amount of surface coverage by oxygen atoms (ii) the bare platinum electrode sites disappear and the oxide phase is formed, changing the nature of the system (iii) the surface oxide may comprise a larger overvoltage due to the effect of a barrier-type oxide film, which affects the kinetics of the electrode reaction occurring at the film/solution interface. This gives rise to a decrease of the over-all apparent transfer coefficient of the electrode reaction, consequently increasing the Tafel slope, as described elsewhere. ${ }^{27}$ Accordingly, the instability, the 
hysteresis and the time effects observed in the initial region of the anodic polarization curve may be attributed to a non-controlled surface oxide formation on the electrode.

At higher potentials where the Tafel slope is definitely established and remains unaltered by gas bubbling including oxygen, the electrode reaction must take place on a platinum electrode completely covered by surface oxide. Then on the basis already discussed, the following reaction paths become very likely:

Scheme III:

$$
\begin{aligned}
2 \mathrm{HSO}_{4}^{-} & \rightleftharpoons \mathrm{SO}_{4}^{2-}+\mathrm{H}_{2} \mathrm{SO}_{4}, \\
\mathrm{SO}_{4}^{2-}+\mathrm{Pt}(\mathrm{O}) & \rightarrow \mathrm{SO}_{3}+\mathrm{Pt}(\mathrm{O}) \cdot \mathrm{O}+2 \mathrm{e}, \\
2 \mathrm{Pt}(\mathrm{O}) \cdot 0 & \rightarrow \mathrm{O}_{2}+2 \mathrm{Pt}(\mathrm{O}), \\
\mathrm{SO}_{3}+\mathrm{SO}_{4}^{2-} & \rightleftharpoons \mathrm{S}_{2} \mathrm{O}_{7}^{2-} .
\end{aligned}
$$

$$
\begin{aligned}
& \mathrm{SO}_{3}+\mathrm{SO}_{4}{ }^{2-} \rightleftharpoons \mathrm{S}_{2} \mathrm{O}_{7}{ }^{2-}, \\
& \mathrm{H}^{+}+\mathrm{HSO}_{4}^{-} \rightleftharpoons \mathrm{H}_{2} \mathrm{SO}_{4} .
\end{aligned}
$$

Assuming as before that reaction (III-1) is very fast, if reaction (III-2) is the rate-determining step, the rate of the electrochemical formation of oxygen, in terms of the apparent anodic $\mathrm{cd}, i_{\mathrm{a}}$, with a simple adsorption isotherm, is

$$
i_{\mathrm{a}}=z F k_{\mathrm{III}-2} \bar{a}_{\mathrm{SO}_{4}{ }^{2-}} \exp \left[\frac{\alpha_{\mathrm{III}-2} F \eta}{R T}\right],
$$

where $k_{\mathrm{III}-2}$ is the specific rate constant, $\bar{a}_{\mathrm{SO}_{4}{ }^{2-}}$ is the activity of sulphate ions on the electrode surface, assumed independent of electrode potential, and $\alpha_{\mathrm{III-2}}$ is the anodic transfer coefficient. Taking for reaction (III-2) a symmetry factor of 0.5 , since the number of electrons entering the rate determining step is $2, \alpha_{\mathrm{III-2}}=1$ and (6) yields the Tafel slope $R T / F$ found in the experiments. The same straightforward conclusion is derived from scheme IV, if reaction (IV-1) becomes the rate-determining step. Then, the rate equation is

$$
i_{\mathrm{a}}=z F k_{\mathrm{IV}-1} \tilde{a}_{\mathrm{HSO}_{\mathrm{s}}}-\exp \left[\frac{\alpha_{\mathrm{IV}-1} F \eta}{R T}\right]
$$

which is formally analogous to (6). The same can also be said if the reaction scheme is written in terms of oxide ions, as already mentioned. Independently of the initial ionic species participating in the discharge reaction, the oxygen-evolution produces no net change of acid in the anode region.

\section{Cathodic reactions}

At low negative overvoltages, before reaching the cathodic limiting current density, instability was observed in the polarization curve. This effect can also be interpreted in terms of the dissolution of oxygen on a platinum surface totally or partially covered. 
In the former case, the reaction path may be formulated:

Scheme V:

$$
\begin{aligned}
\mathrm{Pt}(\mathrm{O})+\mathrm{O}_{2}+2 \mathrm{e} & \rightarrow \mathrm{Pt}(\mathrm{O}) \cdot \mathrm{O}+\mathrm{O}^{2-} \\
\mathrm{Pt}(\mathrm{O}) \cdot \mathrm{O}+2 \mathrm{e} & \rightarrow \mathrm{Pt}(\mathrm{O})+\mathrm{O}^{2-} \\
\mathrm{O}^{2-}+\mathrm{SO}_{3} & \rightleftharpoons \mathrm{SO}_{4}^{2-}
\end{aligned}
$$

If reaction ( $\mathrm{V}-1)$ is the rate-determining step, with simple Langmuir adsorption, when the melt is saturated with oxygen, a Tafel slope equal to $R T / F$ should be observed in the cathodic polarization curve, plotted as $\eta v s \log i$, at high overvoltages. Obviously, kinetic control by reaction (V-2) must in principle be discarded to explain the present results. Nevertheless, in the region of the oxygen-dissolution reaction, the lack of a reliable Tafel slope prevents a definite conclusion. Unfortunately, as it is not clear whether the anodic and cathodic Tafel lines related to oxygen formation and dissolution intersect at the same potential, it is impossible to decide whether or not we are dealing with the same rate-determining step in the two processes. However, (i) the cathodic overvoltages in this potential region are smaller than $R T / F$ (ii) it is likely that the substrate upon which the cathodic data were obtained is significantly different from that on which the anodic ones were obtained, as recently pointed out for oxygen dissolution in aqueous solutions at ordinary temperature, ${ }^{24}$ and finally (iii) it is also possible that at a potential close to the potential of the hydrogen electrode in the melt, the reduction of surface oxides by hydrogen atoms occurs, as observed on platinum black at ordinary temperatures. ${ }^{28}$

The limiting cd in the cathodic region depends on the oxygen pressure. Results obtained for the reduction reaction in the steady as well as the non-steady measurements are in good agreement. Although those experiments were not primarily planned to study oxygen dissolution in the melt under convective diffusion control, it is possible to make a rough estimation of the solubility of the gas in the melt, particularly through the value of the limiting $\mathrm{cd}^{29}$ By taking the diffusion coefficient of molecular oxygen in the melt, $D$, of the order of $10^{-5} \mathrm{~cm} / \mathrm{s}$ and assuming a Nernsttype diffusion layer in natural convection, $\delta$, of $10^{-2} \mathrm{~cm}$, the concentration of dissolved oxygen is of the order of $10^{-7}$ mole/1. These results have led to a detailed study of the oxygen-dissolution reaction under well-defined hydrodynamic conditions, now in progress.

The instability observed in the initial portion of the cathodic line is similar to the effect recently reported for the oxygen-dissolution reaction on platinum in aqueous solutions, ${ }^{24}$ which, at more negative potentials, was attributed to a gradual reduction of surface oxides.

Beyond the limiting current-density region, a cathodic Tafel line is observed with a slope close to $R T / 2 F$. This region corresponds to the hydrogen-evolution reaction, which has been studied in the bisulphate melts under different conditions. ${ }^{4-6}$ The reaction scheme, formally written in terms of hydrogen ions, may be presented, as

Scheme VI:

$$
\begin{gathered}
\mathrm{H}^{+}+\mathrm{Pt}+\mathrm{e} \rightarrow \mathrm{Pt}(\mathrm{H}) \\
\mathrm{Pt}(\mathrm{H})+\mathrm{Pt}(\mathrm{H}) \rightarrow 2 \mathrm{Pt}+\mathrm{H}_{2} .
\end{gathered}
$$

If reaction (VI-1) is rate-determining, then, with a simple double-layer structure, a Tafel slope of $2 R T / F$ should be expected, whereas if reaction (VI-2) is rate-determining, 
the slope should be $R T / 2 F$. This slope has been already observed on platinized platinum electrodes and it is also observed in the present circumstances where undoubtedly the activity of the surface is considerably increased by the reduction of the surface oxides. The extrapolation of the Tafel line to the reversible hydrogen potential $\left(-280 \mathrm{mV}\right.$ at $\left.302^{\circ} \mathrm{C}\right)$ yields an apparent exchange cd of $3 \times 10^{-5} \mathrm{~A} / \mathrm{cm}^{2}$. This figure is slightly lower than that earlier reported for platinized platinum surfaces, but is quite reasonable since a larger actual electrode area deduced from the apparent electrode capacitance must be assigned to the latter. ${ }^{5}$

\section{The decay of anodic overvoltage}

The decay of anodic overvoltage has been recorded at anodic potentials related to the Tafel slope $R T / F$. The decay slope, $b_{\mathrm{d}}$, independent of $c d$, is remarkably coincident with the former. This suggests an apparently simple behaviour of the decay process in the region of the oxygen-evolution reaction, which may be due to the oxidation state of the electrode surface. The apparent electrode capacitance obtained from $t^{\prime}$ is fairly constant over the whole range of potential where the Tafel slope is $R T / F$, and its value is just a little higher than that expected for a simple double layer of the Helmholtz type. This is confirmed by the fact that the electrode capacitance obtained from the build-up of the anode potential, at rest potential, with electrodes previously anodized, yields nearly the same values as those found from the decay curves. Hence, the decay process can be interpreted in principle as that occurring in an equivalent circuit involving the discharge of a capacitor through a faradaic resistance, the latter expressed by a Tafel equation. If $E$ is the anode potential, and $C_{\mathrm{dl}}$ is the experimental double-layer capacitance, a familiar equation is

$$
i_{0} \exp \left[\frac{\alpha_{\mathrm{a}} E}{R T}\right]=-C_{\mathrm{dl}} \frac{\mathrm{d} E}{\mathrm{~d} t}
$$

already known for simple decay processes on electrodes. ${ }^{30.31}$ Integration of (8), assuming $C_{\mathrm{dl}}$ independent of $E$, yields

$$
E=A-b_{\mathrm{d}} \log \left[t+\frac{b_{\mathrm{d}} C_{\mathrm{dl}}}{I_{\mathrm{i}}}\right] .
$$

This equation fits the experimental results very satisfactorily. Thus, the reaction mechanism already mentioned for the oxygen-evolution reaction under steady conditions is also valid for the non-steady process, and the analysis of the latter yields further support to the participation of a completely oxidized platinum surface electrode in the electrochemical process, at least at high positive potentials.

\section{The residual potential}

Although a number of galvanic cells with molten bisulphates were recently described, $\mathbf{4 3 2}$ under the present conditions no definite galvanic cell is formed after current interruption. The rest potential exhibits a characteristic dependence on the electrode treatment and therefore, on its degree of oxidation. When no net current flows through the electrodes, the amount of oxidation depends probably on the previous history of the electrode. This effect, also observed in aqueous systems, ${ }^{25}$ should depend on the $\mathrm{Pt} / \mathrm{Pt}(\mathrm{O})$ ratio. If the latter changes slowly, the rest potential 
changes accordingly. At present it is not possible to consider the residual cell as a cell containing a single oxide as the active species. ${ }^{34}$

\section{The effect of temperature}

Since the more reproducible data are those of the oxygen-evolution reaction, the study of the temperature effect was limited to this, as shown in Table 7. The fact that a reasonable Arrhenius plot can be obtained from these data indicates that there is a single reaction mechanism in the whole temperature range investigated. The experimental activation energies are coincident with the figures obtained recently for the aqueous systems at ordinary temperature. ${ }^{25}$ Furthermore, the apparent exchange cd earlier reported for oxygen evolution from the lithium-sulphate-sodium-sulphate melts at $700^{\circ} \mathrm{C}^{11}$ agrees fairly well with the results from the present work.

Acknowledgement-The present work was done in part with financial support from the Consejo Nacional de Investigaciones Cientificas y Técnicas of Argentina.

\section{REFERENCES}

1. S. Tajima, M. Soda, T. Mori and N. Baba, Electrochim. Acta 1, 205 (1959).

2. F. Le Ber, Rapport C.E.A. R2567. Centre d'Etudes Nucl., Saclay, France (1964).

3. A. M. Shams EL Din, Electrochim. Acta 7, 613 (1962).

4. H. A. Videla and A. J ARvia, Electrochim. Acta 10, 21 (1965)

5. A. J. Arvia, A. J. Calandra and H. A. Videla, Electrochim. Acta 10, 33 (1965).

6. A. J. Arvia, A. J. CAlandra and H. A. Videla, Anal. Asoc. Quim. Arg. 54, 143 (1966).

7 A J. ARVIA, F. DE VegA and H. A. Videla, in preparation.

8. K. J. VetTER, Elektrochemische Kinetik. Springer, Berlin (1961).

9. K. J. Rosental and V. J. Veselowsky, Dokl. Akad. Nauk. S.S.S.R. 111, 637 (1956).

10. P. DelaHAY and C. W. TOBIAS, Advances in Electrochemistry and Electrochemical Engineering, Vol. I, Chap. 3. Wiley, New York (1962).

11. H. FloOd and T. FørlaNd, Discuss. Faraday Soc. 1, 302 (1947).

12. L. A. KING and F. R. DUKe, J. phys. Chem. 68, 1536 (1964).

13. A. J. ARvia, H. A. Videla and A. J. Calandra, in preparation.

14. W. E. Triaca and A. J. Arvia, Electrochim. Acta 10, 409 (1965).

15. A. J. Calandra and A. J. Arvi, Electrochim. Acta 11, 1173 (1966).

16. W. R. Busing and W. Kauzmann, J. chem. Phys. 20, 1129 (1952).

17. F. P. Bowden, Proc. Roy. Soc. A125, 446 (1929).

18. W. Bold and M. W. BreITER, Electrochim. Acta 5, 145 (1961).

19. K. VETTER, op. cit. p. 502.

20. M. W. BREITER and J. L. WEININGER, J. electrochem. Soc. 109, 1135 (1962).

21. S. Gilman, Electrochim. Acta 9, 1025 (1964).

22. A. C. MAKRIDE, J. electrochem. Soc. 113, 1158 (1966).

23. A. Damunovic and J. O'M. Bockris, Electrochim. Acta 11, 376 (1966).

24. A. Damuanovic, A. DeY and J. O’M. Bockris, Electrochim. Acta 11, 791 (1966).

25. J. P. HOARE, Electrochim. Acta 11, 203 (1966).

26. J. J. LINGANe, J. electroanal. Chem. 2, 296 (1961).

27. J. J. McDonald and B. E. Conway, Proc. Roy. Soc. A269, 419 (1962).

28. J. S. MAYELL, J. electrochem. Soc. 113, 385 (1966).

29. P. DelaHay, New Instrumental Methods in Electrochemistry. Interscience, New York (1954).

30. J. A. V. Butler, Trans. Faraday Soc. 28, 379 (1932).

31. B. E. Conway and P. L. Bourgault, Trans. Faraday Soc. 58, 593 (1962).

32. R. P. Seward and J. P. Miller, J. phys. Chem. 69, 3156 (1965).

33. W. J. HAMER, J. electroanal. Chem. 10, 140 (1965). 